\title{
Assistência e cultura material: o património móvel do hospital da Santa Casa da Misericórdia de Pombal na segunda metade do século XIX
}

\author{
Poor Relief and material culture: the mobile assets of Pombal's Santa \\ Casa da Misericórdia hospital at the second half of the 19th century
}

\section{Ricardo Pessa de Oliveira ${ }^{1}$}

\section{RESUMO}

Este artigo tem por objeto de estudo uma instituição que teve, e continua a ter, um papel de suma importância na sociedade, designadamente no que respeita à prestação de cuidados de saúde. Após a fundação da primeira Misericórdia, a de Lisboa, em 1498, assistiu-se a uma difusão célere destas instituições, que passaram a deter o quase monopólio da assistência em Portugal. Este texto estuda uma dessas confrarias de leigos, sob imediata proteção régia, viradas para o exterior, com o propósito de praticar as 14 obras de misericórdia do catecismo cristão: a Santa Casa da Misericórdia de Pombal, irmandade com existência documentada em 1628. Depois de uma breve incursão pelas diferentes fases que a instituição conheceu ao longo da história, o texto debruça-se sobre o edifício do hospital, os assalariados do sector da saúde, os doentes internados e, sobretudo, o património móvel existente naquele espaço na segunda metade de Oitocentos.

Palavras-chave: Portugal, Século XIX, Assistência, Misericórdia, Hospital. ABSTRACT

The purpose of this article is to study an institution which had, and continues to have, a very important role in society, particularly in respect to the healthcare provision. After the foundation of the first Misericórdia there was a fast diffusion of these institutions, which came to have the almost monopoly of assistance in Portugal. This text studies one of these confraternities of laity, under royal protection, facing to society, with the purpose of practicing the corporal and spiritual Works of Mercy: the Santa Casa da Misericórdia of Pombal, a brotherhood with existence documented since 1628. After brief notes about the different phases of the institution throughout history, the text studies the hospital building, salaried employees in the health sector, hospitalized patients and, above all, the movable heritage existing in that space in the second half of $19^{\text {th }}$ century.

Keyword: Portugal, $19^{\text {th }}$ century, poor relief, Misericórdia, Hospital..

1 Universidade Aberta, Cátedra Infante D. Henrique para os Estudos Insulares Atlânticos e a Globalização (CIDH) / Universidade de Lisboa, Faculdade de Letras, Centro de Literaturas e Culturas Lusófonas e Europeias (CLEPUL). 
1. Com existência documentada em 1628, a Santa Casa da Misericórdia de Pombal conheceu, como qualquer outra instituição, diferentes fases ao longo da sua história. ${ }^{2}$ Apesar da escassez de documentação para os séculos XVII e XVIII, resultado da destruição do seu arquivo aquando da terceira Invasão Francesa (1810-1811), esse parece ter sido um período de consolidação e de crescimento. No início de Setecentos, o padre António Carvalho da Costa afirmou que a Santa Casa possuía bastante renda, proventos que aumentaram no decurso dessa centúria, resultado da receção de vários legados, quase todos encapelados, com destaque para os bens de raiz deixados em testamento pelos pombalenses Manuel Teixeira de Carvalho, fidalgo da Casa Real, familiar do Santo Ofício e secretário da Mesa da Consciência e Ordens; e frei Valentim Alexandre da Cunha, beneficiado na colegiada de São Martinho da vila de Pombal. ${ }^{3} \mathrm{Na}$ década de 70, dessa centúria, a irmandade acentuou a sua relação com o poder, elegendo como provedor Sebastião José de Carvalho e Melo, marquês de Pombal, aliando ao capital simbólico novas mercês (OLIVEIRA, 2016a, 92-93). Porém, na última década do século XVIII, principiou uma fase distinta, caracterizada por decadência, desordem e delapidação dos bens, consequência da incúria de determinados mesários e tesoureiros das capelas. A esses aspetos somaram-se fraudes eleitorais que obrigaram, inclusivamente, à intervenção da Coroa. ${ }^{4}$

A terceira Invasão Francesa agravou a situação da confraria. O extravio do cartório originou confusão sobre o património da Casa e dificuldade em reconhecer os devedores de foros, juros e rendas. Para solucionar o problema, em 1813, os mesários alcançaram uma provisão régia para que o juiz de fora da vila elaborasse novo tombo dos bens da irmandade. No entanto, em março de 1827, o mesmo, por dispendioso, ainda não fora iniciado, o que resultava em claro prejuízo para a Santa Casa, tanto mais que alguns dos antigos

\footnotetext{
${ }^{2}$ Nas últimas décadas, as Misericórdias têm merecido uma atenção crescente e sistemática por parte dos investigadores. Os estudos têm privilegiado, sobretudo, a Época Moderna e menos o período contemporâneo. Entre os autores que se têm dedicado a esta temática cf. SÁ, Isabel dos Guimarães. Quando o rico se faz pobre: Misericórdias, caridade e poder no império português 1500-1800. Lisboa: Comissão Nacional para as Comemorações dos Descobrimentos Portugueses, 1997; Idem. As Misericórdias Portuguesas de D. Manuel I a Pombal. Lisboa: Livros Horizonte, 2001; ABREU, Laurinda. A Santa Casa da Misericórdia de Setúbal de 1500 a 1755: Aspectos de sociabilidade e poder. Setúbal: Santa Casa da Misericórdia de Setúbal, 1990; Idem. Memórias da Alma e do Corpo. A Misericórdia de Setúbal na Modernidade. Viseu: Palimage Editores, 1999; LOPES, Maria Antónia. Pobreza, Assistência e Controlo Social em Coimbra (1750-1850). 2 vols. Viseu: Palimage Editores, 2000; ARAÚJO, Maria Marta Lobo de. Dar aos pobres e emprestar a Deus: as Misericórdias de Vila Viçosa e Ponte de Lima (Séculos XVI-XVIII). Barcelos: Santa Casa da Misericórdia de Vila Viçosa, Santa Casa da Misericórdia de Ponte de Lima, 2000; Idem. A Misericórdia de Vila Viçosa: de finais do Antigo Regime à República. Vila Viçosa: Santa Casa da Misericórdia de Vila Viçosa, 2010. Cf., igualmente, PAIVA, Jo'se Pedro (coord.). Portugaliae Monumenta Misericordiarum. 9 vols. Lisboa: União das Misericórdias Portuguesas, 2002-2011. Para a Época Contemporânea, além dos trabalhos de Maria Antónia Lopes e de Maria Marta Lobo de Araújo, refira-se alguns dos textos recentemente publicados em ARAÚJO, Maria Marta Lobo de (coord.), A Intemporalidade da Misericórdia. As Santas Casas Portuguesas: Espaços e Tempos. Braga: Santa Casa da Misericórdia de Braga, 2016; REIS, Célia. A Misericórdia de Torres Vedras (1520-1975). Torres Vedras: Santa Casa da Misericórdia de Torres Vedras, 2016; e OLIVEIRA, Ricardo Pessa de. História da Santa Casa da Misericórdia de Pombal (1628-1910). Pombal: Santa Casa da Misericórdia de Pombal, 2016. No presente texto retomamos e sintetizamos alguma da investigação dada a conhecer nessa obra.

${ }^{3}$ COSTA, António Carvalho da. Corografia Portugueza, e Descripçam Topografica do Famoso Reyno de Portugal. Tomo III. Lisboa: Oficial Real Deslandesiana, 1712, p. 105; Pombal, Arquivo da Santa Casa da Misericórdia de Pombal (A.S.C.M.P.), Livro de títulos da Santa Casa de Pombal (1821), fols. 81-84; Pombal, A.S.C.M.P., Breves para redução de missas e encargos pios, fols. 22-29v.

${ }^{4}$ Lisboa, Arquivo Nacional Torre do Tombo (A.N.T.T.), Desembargo do Paço, Corte, Estremadura e Ilhas, mç. 647, doc. 31.
} 
administradores, que poderiam elucidar sobre a matéria, haviam, entretanto, falecido. ${ }^{5} \mathrm{~A}$ essas contrariedades, acresceu o estrago causado na igreja da instituição e nas propriedades aforadas, o que obrigou inclusive ao abatimento de alguns foros. Saliente-se ainda a redução drástica no número de irmãos. Se em julho de 1802, a corporação afirmou contar com mais de 40 irmãos de primeira condição e mais de 100 de qualidade inferior; em 1823, foram apenas arrolados 53 membros: 32 nobres e 21 oficiais. $^{6}$

Nos anos seguintes, persistiram indícios de gestão ruinosa. Em 1827, o juiz de fora de Pombal acusou a irmandade de administrar muito mal as suas rendas; e em 1831, no seguimento de uma eleição controversa, em que fora eleito para a provedoria um indivíduo que não era irmão, o provedor da comarca referiu-se à irmandade utilizando os vocábulos abandono, desarranjo e desmazelo (OLIVEIRA, 2016a, 148).

Com a criação dos governos civis, em 1834, acentuou-se a intervenção do poder central nas Misericórdias, que passaram a estar sujeitas à fiscalização dos governadores civis de distrito e dos administradores de concelho. Compromissos, contas, eleições, mapas de doentes e orçamentos, tudo tinha de ser comunicado e aprovado pelo governo civil do distrito. ${ }^{7} \mathrm{O}$ Estado pretendia colocar termo a excessos e a administrações ruinosas, pelo que concedeu poderes aos seus representantes para poderem intervir na gestão destas instituições (ARAÚJO, 2010, 416). Não obstante, a situação da Misericórdia manter-se-ia muito difícil. Teve de lidar com constantes dificuldades financeiras, para o que muito contribuiu a difícil cobrança de juros e de foros, problema crónico, a que nenhuma Mesa ou comissão administrativa escapou e que obrigou ao recurso sistemático à justiça. O processo da venda do património não necessário às atividades pias e beneficentes, ordenado em 1866, acabou por constituir um golpe para a Misericórdia, ainda que os seus efeitos não tenham sido sentidos no imediato. A alienação desse património, realizada na capital de distrito, sem intervenção da irmandade, conduziu à arrematação de bens por preços irrisórios, realidade que provocou uma diminuição considerável no rendimento da Casa. A redução em 30 por cento dos juros dos títulos de dívida pública, decretados em 1892, representou outro revés para a irmandade pois ainda que tenha conseguido obter do governo o subsídio igual ao valor da dedução decretada, o mesmo não era pago em tempo oportuno (OLIVEIRA, 2016a, 150-152)

2. A instituição em apreço veio, à semelhança de muitas congéneres, a anexar e a administrar o único hospital existente na vila (SÁ, 2010, 24-27). Embora desconheçamos o momento exato em que assumiu a responsabilidade pela assistência hospitalar já o fazia em 1670 (OLIVEIRA, 2016a, 199-200). Localizado na rua do Espírito Santo, paredes-meias com a

\footnotetext{
${ }^{5}$ Lisboa, A.N.T.T., Desembargo do Paço, Corte, Estremadura e Ilhas, mç. 802, doc. 1; mç 1560, doc. 9.

${ }^{6}$ Lisboa, A.N.T.T, Desembargo do Paço, Corte, Estremadura e Ilhas, mç. 647, doc. 31; Pombal, A.S.C.M.P., Livro primeiro das entradas dos irmãos, fols. 2-6v.

${ }^{7}$ Leiria, Arquivo Distrital de Leiria (A.D.L.), Governo Civil de Leiria, Licenciamento e Fiscalização, Santa Casa da Misericórdia de Pombal, 01-III-74-D-4.
} 
igreja da instituição e com a casa do despacho, era um espaço bastante reduzido com manifesta falta de condições, no qual eram recolhidos doentes e pobres em trânsito, ainda que provavelmente em divisões distintas, não tendo, ao que tudo indica, sofrido grandes alterações até ao final do século XVIII.

No início da centúria seguinte, após uma grave epidemia que assolou a região, a Misericórdia erigiu e administrou um novo hospital, com capacidade para seis doentes, espaço que funcionou entre 1802 e 1808, tendo o avolumar de despesas e o acumular de dívidas acabado por ditar o encerramento do espaço. ${ }^{8}$ Nos anos imediatos, pese a contradição das fontes estudadas, a irmandade continuou a assegurar alguma assistência hospitalar, providenciando três ou quatro camas, na casa do hospital, para recolher e tratar outros tantos enfermos. ${ }^{9}$ Entretanto, foram sendo realizadas obras no edifício, sem que tal significasse uma melhoria efetiva das condições. Em 1858, o administrador do concelho ao relatar as limitações do estabelecimento afirmou tratar-se de "uma pequena Caza de Mezericordia [...] á qual não posso chamar hospital, tem ambito para receber trez ou quatro doentes e os rendimentos d'ella que não chegão a $300 \$ 000$ reis não podem supprir as necessidades de tantos desgraçados". ${ }^{10}$

Em 1864 e em 1871, tiveram lugar novas intervenções no edifício, que incluíram a construção de uma nova enfermaria, na casa da tribuna. Ainda assim, a capacidade do espaço manteve-se insuficiente. As enfermarias eram de tal forma reduzidas que as camas estavam "quaze juntas" o que impossibilitava o vigário "de poder ouvir debaixo de cygillo (sic) as declarações em acto de confissão dos infermos em p[e]rigo de vida". ${ }^{11} \mathrm{~A}$ esse aspeto acrescia a insalubridade do edifício, já que as casas destinadas para o efeito, além de térreas, eram pequenas, húmidas, sem ventilação e destituídas de todas as condições higiénicas. ${ }^{12}$

As décadas de 70 e de 80 do século XIX ficaram marcadas pelo desejo de construir um novo hospital, tendo sido delineados distintos projetos. Como todos os planos gizados acabaram por fracassar, em 1879, os irmãos deliberaram proceder à reedificação completa do hospital, tendo os trabalhos decorrido entre 1882 e $1884 .{ }^{13}$ No entanto, apenas funcionaria naquele local até 22 de março de 1889, data em que foi instalado num solar notável, situado no largo da Ponte Pedrinha, doado para o efeito, um ano antes, por uma benfeitora. ${ }^{14}$ Entre outras

\footnotetext{
${ }^{8}$ Lisboa, A.N.T.T, Desembargo do Paço, Corte, Estremadura e Ilhas, mç. 1560, doc. 9.

${ }^{9}$ Lisboa, A.N.T.T, Desembargo do Paço, Corte, Estremadura e Ilhas, mç. 1560, doc. 9.

${ }^{10}$ Leiria, A.D.L., Governo Civil, Correspondência de Administradores do Concelho, cx. 5 (1848-1863), III-47-E-1, doc. não numerado (1858).

${ }^{11}$ Pombal, A.S.C.M.P., Livro de atas (1871-1878), fol. 17. Para fazer face aos ditos inconvenientes o vigário solicitou um biombo para poder ouvir as confissões dos doentes, tabique que teve um custo de 3.185 réis, cf. Pombal, A.S.C.M.P., Diário da receita e despesa (1871-1874), fols. 88 e 89.

${ }^{12}$ Leiria, A.D.L., Governo Civil, Correspondência de Administradores do Concelho, cx. 6 (1864-1885), III-47-E-2, doc. não numerado; MORA, Amadeu Cunha. Esboço Histórico da Santa Casa da Misericórdia de Pombal. Pombal: Santa Casa da Misericórdia de Pombal, 2010 (reimpressão da edição de 1953), p. 69.

${ }^{13}$ Pombal, A.S.C.M.P., Livro de atas (1878-1884), fols. 10-10v.

${ }^{14}$ Pombal, A.S.C.M.P., Livro de atas (1884-1903), fols. 32v-33 e 38-40v. Sobre as questões relativas à doação, cf. MORA, Amadeu Cunha. Esboço Histórico [...], pp. 76-79.
} 
benfeitorias o imóvel possuía um jardim, com várias árvores de fruto e um poço de água nativa, com pia de pedra. Por sua vez, o quintal possuía um alpendre para recolher lenha, um forno para cozer pão e uma pia de água para serviço da cozinha. ${ }^{15}$

Apesar das condições terem melhorado substancialmente a capacidade do espaço continuou a ser bastante limitada. Em novembro de 1900, em resposta a um ofício do administrador do concelho, afirmou-se que o hospital tinha apenas quatro camas. ${ }^{16}$ Para melhorar esse aspeto e proporcionar o internamento a doentes que em virtude das suas moléstias não podiam ser admitidos, em março de 1907, a irmandade mandou reparar dois quartos existentes nas dependências do edifício, para que pudessem servir de isolamento a enfermos com doenças contagiosas. ${ }^{17}$

3. A análise da receita e despesa da irmandade evidenciou mudanças de vulto ocorridas no século XIX. Se no final da década de 30, a Misericórdia canalizava a maior parte dos seus recursos para o sector religioso (obras na sua igreja, festividades religiosas e pagamento do ordenado ao capelão), nas décadas seguintes o cenário modificou-se, passando a canalizar a maior fatia da despesa para o sector da saúde (esmolas a doentes pobres, dietas, remédios ministrados a enfermos internos e externos, custas hospitalares de doentes remetidos para outros hospitais, obras de reconstrução e melhoramento do hospital da instituição, salários do pessoal do hospital).

De resto, o texto normativo da Misericórdia de Pombal, aprovado e publicado em 1873, foi claro ao afirmar que "presentemente a principal obrigação d'esta Santa Caza é accorrer ás necessidades do seu hospital". ${ }^{18}$ Posto isto, não podemos deixar de estranhar a posição ocupada pelas determinações referentes àquele espaço, nem tão-pouco a exiguidade dos artigos consagrados à matéria..$^{19} \mathrm{O}$ tema foi tratado nos artigos $51 .^{\circ}, 52 . .^{\circ}$ e $53 . .^{\circ}$ do capítulo sete. Através das concisas resoluções, é possível verificar duas realidades. Por um lado, o estado financeiro delicado da Santa Casa. Tal como requerido a propósito das festas religiosas, também no hospital deveria existir desvelo para conter as despesas, sendo necessário "capitalizar qualquer quantia" de forma a poder socorrer o maior número possível de desgraçados. ${ }^{20}$ Por outro lado, os limites do hospital. Em três artigos, dois foram consagrados à remessa de doentes para outros estabelecimentos, no caso das moléstias não puderem ser

\footnotetext{
${ }^{15}$ Leiria, A.D.L., Registos Notariais, Pombal, V-104-A-56, fols. 33-33v.

${ }^{16}$ Pombal, A.S.C.M.P., Registo da correspondência expedida (1875-1935), fol. 117.

${ }^{17}$ Pombal, A.S.C.M.P., Livro de atas (1903-1910), fols. 51v-52.

${ }^{18}$ Leiria, A.D.L., Governo Civil de Leiria, Licenciamento e Fiscalização, Santa Casa da Misericórdia de Pombal, 01-III-74-D-4, Compromisso da Santa Casa da Misericórdia de Pombal, cap. 7, art. 51.

${ }^{19}$ Nesse período, várias Misericórdias optaram por apresentar, nos seus compromissos, as normas relativas ao hospital em último lugar. É paradigmático, o texto da Santa Casa de Vila Viçosa de 1881, cf. ARAÚJO, Maria Marta Lobo de Araújo. $A$ Misericórdia de Vila Viçosa [...], p. 31.

${ }^{20}$ Leiria, A.D.L., Governo Civil de Leiria, Licenciamento e Fiscalização, Santa Casa da Misericórdia de Pombal, 01-III-74-D-4, Compromisso da Santa Casa da Misericórdia de Pombal, cap. 7, art. 51.
} 
tratadas naquele espaço. Tal facto esclarece sobre os limites que as condições e dimensões do hospital de Pombal e, outrossim, as terapias oferecidas impunham.

A escassez de disposições relativas a esta matéria teve como principal razão o desígnio de prover aquele espaço de um regulamento interno. Tal ideia colhe-se em sessão de 13 de fevereiro de 1874. Nesse dia, a Mesa quando questionada por Francisco António dos Reis, médico-cirúrgico, deliberou que enquanto não existisse regulamento privativo do hospital e os fundos da instituição não aumentassem consideravelmente, ficasse ao arbítrio do requerente, ou de outro qualquer facultativo, "entender-se com os doentes que quizerem entrar no hospital mediante a quantia de duzentos e quarenta reis diarios, por forma que elles satisfizessem aquella quantia ou quantias que os mesmos facultativos entendessem ser-lhes devida pelo seu trabalho". ${ }^{21}$ Posteriormente, em sessão de 9 de julho de 1879 , foi nomeada uma comissão, composta por três membros, para formular o regulamento interno do estabelecimento. ${ }^{22}$ Nos livros de atas não existe qualquer outra referência ao mencionado regimento, nem tão-pouco aos trabalhos da comissão nomeada para redação do mesmo. Ainda assim, através do registo de correspondência expedida, sabemos que os trabalhos tiveram prosseguimento. A 31 de julho de 1879, foi remetido um ofício aos hospitais de Alcobaça, da Figueira da Foz e de Leiria solicitando um exemplar das regras daqueles espaços, para servirem de base às do hospital de Pombal. ${ }^{23}$ Mais tarde, a 6 de março de 1880, os vogais da dita comissão foram convocados para comparecer na sala das sessões, no dia 8, pelas 18 horas, a fim de tratar das ditas normas. ${ }^{24}$ Sendo esta a derradeira menção localizada, é de crer que o regulamento não tenha sido concluído, não tendo sido alcançado o propósito da Mesa de "remediar tão grande falta". 25

4. Para assistir os doentes internados no hospital, a Santa Casa contou entre os seus assalariados com médicos e enfermeiros. Até meados do século XIX, a instituição não concedeu qualquer remuneração aos facultativos que visitavam e tratavam os doentes admitidos no hospital. Essa assistência era assegurada pelo médico do partido da vila que, em virtude do contrato assinado com a câmara, tinha a obrigação de curar todos os pobres da vila e termo, incluindo os admitidos no hospital. ${ }^{26}$ Só em 1857, é que a comissão administrativa,

\footnotetext{
${ }^{21}$ Pombal, A.S.C.M.P., Livro de atas (1871-1878), fol. 59.

${ }^{22}$ Pombal, A.S.C.M.P., Livro de atas (1878-1884), fol. 28.

${ }^{23}$ Pombal, A.S.C.M.P., Registo da correspondência expedida (1875-1935), fols. 22-22v.

${ }^{24}$ Pombal, A.S.C.M.P., Registo da correspondência expedida (1875-1935), fol. 24v.

${ }^{25}$ Pombal, A.S.C.M.P., Registo da correspondência expedida (1875-1935), fols. 22-22v.

${ }^{26}$ Lisboa, A.N.T.T., Desembargo do Paço, Corte, Estremadura e Ilhas, mç. 125, doc. 39. Em 1758, o facultativo auferia 100.000 réis anuais, fintados no cabeção da sisa, cf. Lisboa, A.N.T.T., Desembargo do Paço, Corte, Estremadura e Ilhas, mç. 125, doc. 28. Em 1795, essa quantia duplicou, passando para 200.000 réis, cf. Lisboa, A.N.T.T., Desembargo do Paço, Corte, Estremadura e Ilhas, mç. 641, doc. 6. A propósito cabe referir que a carta régia de 4 de junho de 1624, que aprovou o estabelecimento de um partido médico na Guarda, pretendido pelo senado daquela cidade, acrescentou que o facultativo seria obrigado a curar gratuitamente os frades de São Francisco e todos os pobres, assim do Hospital como fora dele, obrigação que passaria a ser imposta "nos partidos semelhantes, que se concederam em quaesquer logares do reino", cf. Collecção Chronologica da Legislação Portugueza, compilada e anotada por José Justino de Andrade e Silva, 1620-1627. Lisboa: Imprensa de J. J. A. Silva, 1855, p. 122.
} 
que então regia a Misericórdia, considerou ser útil "para esta Santa Caza haver um medico que dando se uma modica gratificação se quizesse encarregar dos doentes entrados neste hospital". ${ }^{27}$ Desta forma, a irmandade passou a contar, entre os seus assalariados, com um médico da Casa com o ordenado de 12.000 réis anuais. No entanto, no final de 1863, a irmandade optou por abolir o lugar, considerando tratar-se de uma despesa desnecessária, porquanto existia um médico do partido da vila que era obrigado a curar gratuitamente os pobres "e por isso os infermos que entrão no hospital desta Santa Caza, como tal clasificados". ${ }^{28}$

Uma década depois, foram os próprios facultativos a requerer um ordenado pelos serviços prestados no hospital invocando, além do acréscimo das rendas da Santa Casa, o aumento do número de doentes. ${ }^{29}$ Pese o assunto não ter gerado consenso, a Mesa acabou por conceder o ordenado de 15.000 réis anuais ao médico Miguel Pinto Cota Coelho de Araújo e ao médico-cirurgião Francisco António dos Reis. ${ }^{30}$ Pouco depois, em maio de 1876, os mesmos facultativos, alegando, uma vez mais, o aumento do trabalho clínico, solicitaram que a sua remuneração fosse elevada a 30.000 réis anuais. ${ }^{31}$ Debatido ao longo de várias sessões e sem gerar unanimidade, o pedido acabou por ser atendido, ficando todavia impossibilitados de receber honorários pelo tratamento de doentes particulares entrados no hospital. ${ }^{32} \mathrm{Em}$ abril de 1888, a verba destinada ao pagamento dos facultativos foi novamente eliminada por "motivos imperiosos". Para tal, o provedor, na qualidade de vereador da câmara, conseguira, em sessão camarária e a pedido dos restantes mesários, que os médicos do partido da vila fossem obrigados a tratar gratuitamente todos os doentes do hospital "salvo a faculdade por parte da Misericórdia de gratificar como e quando entender os serviços prestados por aqueles facultativos". ${ }^{33}$. Em 1890/91, acabou por ser restituída a verba de 30.000 réis para um facultativo, valor que seria reduzido para 18.000 réis em 1893, em virtude de Manuel Rodrigues Pinto, médico da Casa, ter resolvido ceder 12.000 réis para ordenado do enfermeiro, que considerava diligente e mal remunerado. ${ }^{34}$

Se na Época Moderna, a Misericórdia contou com um casal de hospitaleiros que, além da limpeza e manutenção do edifício do hospital, teria a seu cargo a alimentação dos doentes e a administração dos medicamentos prescritos pelo médico do partido municipal (OLIVEIRA, 2016a, 382-388), na década de 1840 a instituição não contava sequer com uma enfermeira permanente, talvez porque, além do número de admitidos não o exigir, as condições

\footnotetext{
${ }^{27}$ Pombal, A.S.C.M.P., Livro de atas (1844-1862), fols. 118-118v.

${ }^{28}$ Pombal, A.S.C.M.P., Livro de atas (1862-1871), fol. 24.

${ }^{29}$ Pombal, A.S.C.M.P., Livro de atas (1871-1878), fol. 36.

${ }^{30}$ Pombal, A.S.C.M.P., Livro de atas (1871-1878), fols. 37-37v.

${ }^{31}$ Pombal, A.S.C.M.P., Livro de atas (1871-1878), fols. 103v-104.

${ }^{32}$ Pombal, A.S.C.M.P., Livro de atas (1871-1878), fols. 105v, 107-108.

${ }^{33}$ Pombal, A.S.C.M.P., Livro de atas (1884-1903), fols. 32-32v.

${ }^{34}$ Pombal, A.S.C.M.P., Livro de atas (1884-1903), fol. 46v; Pombal, A.S.C.M.P., Livro de atas (1884-1903), fols. 65-65v. Após a morte do enfermeiro, o facultativo requereu a quantia anteriormente cedida, cf. Pombal, A.S.C.M.P., Livro de atas (18841903), fol.71v. Pese o pedido ter sido deferido (como se comprova no orçamento para o ano de 1894/95), os registos de receita e despesa atestam que os médicos continuaram a auferir apenas 18.000 réis.
} 
financeiras da Casa assim o impunham. Por isso, quando necessário, a irmandade optava por contratar uma mulher para ministrar os medicamentos e as refeições aos enfermos admitidos no hospital, trabalho que cessava quando o doente tinha alta ou morria. ${ }^{35}$

No final de 1857, a irmandade passou a contar com uma enfermeira a tempo inteiro, com o ordenado de 12.000 réis anuais. ${ }^{36}$ No entanto, a permanência dessa assalariada acabou por ser efémera, já que a 20 de julho de 1859, a Mesa decidiu suspender o lugar de enfermeira "pelo julgar desnecessario e não haver hospital regular, e a Caza não ter meios". ${ }^{37}$ Assim, no ano económico que então principiava voltamos a encontrar pagamentos irregulares a mulheres que tratavam dos doentes quando necessário. Só a 6 de agosto de 1863, a Mesa decidiu contratar uma pessoa que se "quizesse encarregar da enfermaria do hospital tractando e zelando os doentes que ali entrassem, fazendo-lhe a comida, dando-lhe remedios e prestandolhe todos os serviços de que os doentes carecessem". ${ }^{38}$

Apesar do compromisso de 1873 ter estabelecido a existência de um enfermeiro, este continuava a não existir. Somente em março de 1875, após requerimento da enfermeira Mariana Alves de Araújo e do parecer de um dos vogais da Mesa, que servira de mordomo do hospital, ${ }^{39}$ foi finalmente criado o lugar de ajudante de enfermeira, que seria provido por intermédio de concurso. ${ }^{40} \mathrm{~A}$ principal tarefa deste assalariado consistia no acompanhamento dos doentes do sexo masculino, auxiliando certas operações "a que não deve assistir a enfermeira em razão do seu sexo". ${ }^{41}$ Estava ainda obrigado a acompanhar os enfermos quando, por algum motivo, necessitavam de ser observados pelo facultativo noutro local e a lavar e amortalhar, com a ajuda da enfermeira, os doentes que pereciam no hospital. ${ }^{42} \mathrm{~A}$ remuneração do enfermeiro ajudante, sempre o marido da enfermeira, era bastante exígua, quando comparada com o da esposa. Quando o lugar foi criado, o ordenado foi fixado em 12.000 réis anuais, ou seja, menos 60.000 réis do que a enfermeira. ${ }^{43}$

\footnotetext{
${ }^{35}$ Tenhamos em consideração que as competências das enfermeiras eram bastante distintas das atuais. Acrescente-se que, até finais do século XIX, período em que surgiram as primeiras escolas de enfermagem portuguesas, apenas se exigia que os candidatos a enfermeiros soubessem ler, escrever e contar, cf. SILVA, Ana Isabel. A Arte de Enfermeiro: Escola de Enfermagem Dr. Ângelo da Fonseca. Coimbra: Imprensa da Universidade de Coimbra, 2008, p. 31-45; SILVA, Helena Sofia Rodrigues Ferreira da. Do curandeiro ao diplomado: história da profissão de enfermagem em Portugal (1886-1955). Tese (Doutorado em História, área de conhecimento Idade Contemporânea) - Universidade do Minho, Braga, 2010.

${ }^{36}$ Pombal, A.S.C.M.P., Livro de atas (1844-1862), fols. 120v-121.

${ }^{37}$ Pombal, A.S.C.M.P., Livro de atas (1844-1862), fol. 135.

${ }^{38}$ Pombal, A.S.C.M.P., Livro de atas (1862-1871), fol. 17.

${ }^{39}$ Eleito, preferencialmente, entre os irmãos vogais da Mesa, o mordomo do hospital, devia servir por espaço de três meses, cabendo-lhe assegurar o bem-estar dos doentes. Além de fiscalizar o labor dos enfermeiros, estava incumbido de atestar a correcta admissão dos enfermos, não devendo admitir mendigos sem o competente atestado de pobreza passado pelo pároco, informação do médico e despacho do provedor. Apenas os doentes em estado mais grave, poderiam ser prontamente admitidos, já que a sua condição não compadecia as demoras que tal burocracia envolvia.

${ }^{40}$ Pombal, A.S.C.M.P., Livro de atas (1871-1878), fols. 80v e 81v.

${ }^{41}$ Leiria, A.D.L., Governo Civil de Leiria, Licenciamento e Fiscalização, Santa Casa da Misericórdia de Pombal, 01-III-74-D-4, doc. não numerado.

${ }^{42}$ Pombal, A.S.C.M.P., Registo da correspondência expedida (1875-1935), fols. 66v-67; Pombal, A.S.C.M.P., Livro de atas (18841903), fol. 52.

${ }^{43}$ Pombal, A.S.C.M.P., Livro de receita e despesa (1869-1905), fol. 16.
} 
A relação da Misericórdia com estes assalariados foi bastante conturbada. Ao longo da segunda metade do século XIX, a instituição tomou conhecimento de diversas faltas graves, acabando por despedir a quase totalidade dos enfermeiros. A longa lista das transgressões incluiu: a) permissão de entrada no hospital a pessoas estranhas, durante a noite; b) falta de caridade e de zelo para com os doentes; c) despesas desnecessárias, tendo unicamente em vista o cómodo pessoal; d) recusa em lavar e amortalhar indivíduos falecidos no hospital; e) consumo do receituário da Casa, sem autorização; f) consumo de dietas destinadas a enfermos (OLIVEIRA, 2016a, 395-396).

Durante um curto período, a Misericórdia contou com um outro assalariado, ligado ao sector da saúde: o servente do hospital. Este empregado, cuja primeira referência data de maio de 1873, tinha como tarefa o despejo diário das imundícies dos internados. Até então, os excrementos eram depositados no pátio das instalações, o que evidentemente representava um foco de infeções, prejudiciais à saúde de doentes e de empregados. ${ }^{44}$ Por esse motivo, os mesários acordaram ajustar uma mulher para proceder ao referido despejo, tendo sido adquirido, para o efeito, um depósito de lata, de grandes dimensões. ${ }^{45}$ Entre maio de 1873 e abril de 1884, último mês em que a função foi referida, foi sempre desempenhada por Maria Perpétua, que auferia 10.800 réis por ano. ${ }^{46}$

5. O estabelecimento foi procurado tanto por homens como por mulheres. Ainda assim, existiu um ligeiro predomínio de doentes do sexo masculino: 56,8 por cento, contra 43,2 por cento de mulheres. Os internados eram maioritariamente solteiros e residentes no concelho de Pombal. Posto que tenham sido internados doentes de praticamente todas as idades, o universo em estudo era constituído essencialmente por gente adulta, com destaque para os enfermos com idade igual ou superior a 50 anos, grupo etário que representou 26,8 por cento do total de admitidos. Ainda assim, o grupo constituído pelas crianças e pelos jovens não deixou de ser particularmente relevante, tendo atingindo uma percentagem de 29,6. Relativamente ao estatuto socioprofissional, estamos em presença de gente pertencente a baixos estratos sociais, com destaque para os indivíduos ligados ao sector agro-pastoril (25,5 por cento) e à criadagem (21,8 por cento). Por sua vez, os pobres e os marginais representaram 7,3 por cento do total de admitidos. Entre os primeiros foram arrolados 84 mendigos, 23 pobres, dois pedintes e um indigente. Quanto aos marginais, as fontes assinalaram cinco vadias e três prostitutas. A clientela hospitalar era, portanto, como em espaços congéneres do

\footnotetext{
${ }^{44}$ Pombal, A.S.C.M.P., Livro de atas (1871-1878), fols. 35-35v.

${ }^{45} \mathrm{O}$ depósito, comprado ao latoeiro Manuel Trino, teve um custo de 1.600 réis, cf. Pombal, A.S.C.M.P., Diário da receita e despesa (1871-1874), fol. 105.

${ }^{46} \mathrm{Em}$ maio de 1884, os doentes foram transferidos para o hospital reconstruído. Assim, ou as novas instalações tornaram dispensável esta funcionária, ou a situação da Casa, fruto das avultadas despesas com as referidas obras, obrigou ao corte de pessoal. De referir que nos anos económicos de 1874/75 e 1875/76, o lugar de servente não foi arrolado no livro de receita e despesa, cf. Pombal, A.S.C.M.P., Livro de receita e despesa (1869-1905), fols. 14 e 16. A existência da servente nesses anos é comprovada pelo diário da receita e despesa.
} 
passado, maioritariamente constituída por gente pobre ou pauperizável. De resto, apenas uma minoria tinha capacidade para pagar o internamento (OLIVEIRA, 2016a, 233-240).

O movimento de entrada de doentes não foi uniforme. A década de 70 do século XIX foi aquela que registou maior número de entradas, com a admissão de 623 doentes: 348 do sexo masculino e 275 do sexo feminino. Seguiu-se a década de 80 com a hospitalização de 415 indivíduos: 213 homens e 202 mulheres. Durante essas duas décadas, destaque para o período compreendido entre 1873 e 1881, em que foram hospitalizados, em média, 73 doentes por ano. A malária, associada à insalubridade dos arrozais, representou um grave problema de saúde pública no concelho de Pombal, tendo concorrido para o aumento de internamentos ocorrido nesse período. ${ }^{47}$ Posteriormente o número de doentes admitidos decresceu bastante de tal forma que, entre 1886 e 1910, a média anual foi apenas de 26.

A causa da enfermidade nem sempre foi registada. Nos casos em que a moléstia foi designada, foi possível verificar um número significativo de doenças infeciosas. A par de infectocontagiosas de índole diversa, como a febre tifoide, a gonorreia, o sarampo, a sífilis, a tuberculose e a varíola, cujas ocorrências foram pouco expressivas, até porque o hospital não possuía condições para receber esses enfermos, cabe salientar, como já referido, a malária, correntemente designada por febres palúdicas, que atingiu proporções bastante significativas. Além dessa enfermidade, destaque para os internamentos motivados por ferimentos. Referimo-nos a contusões, esmagamentos, fraturas, mordeduras, picadas, traumatismos e úlceras. Se algumas das feridas haviam resultado de acidentes de trabalho ou de viajem, outras haviam sido ocasionadas por espancamentos e por rixas. Entre as restantes patologias, os problemas gastrointestinais, tais como ascites, enteralgias, enterocolites, gastralgias, gastrites e gastroenterites; e pneumológicos, de que são exemplos apoplexias pulmonares, broncorreias, bronquites, pleurites e pneumonias, tiveram igualmente algum peso. Menos significativos foram os problemas cardíacos, dermatológicos, ginecológicos/obstétricos, hepáticos, mentais, oftalmológicos, reumáticos e urológicos.

A maioria dos doentes teve alta hospitalar. $O$ tratamento aplicado a 79,5 por cento das mulheres foi bem-sucedido. No que respeita aos homens, a taxa de cura foi ainda mais elevada, já que 81,4 por cento dos admitidos alcançaram a cura ou, pelo menos, registaram melhoras a ponto de possibilitar a alta hospitalar. Quanto à duração do internamento, entre os que tiveram alta, a maior parte, tanto homens como mulheres, permaneceu hospitalizada entre oito e 29 dias. ${ }^{48}$ Bastante significativos foram ainda os internamentos entre um e três

${ }^{47}$ A propósito da cultura do arroz em Portugal, cf., a síntese apresentada por CASTRO, Armando de. "Orizicultura". In: SERRÃO, Joel (dir.). Dicionário de História de Portugal. Vol. IV. Lisboa: Pário, Porto: Livraria Figueirinhas, 1984, p. 479-481. Para o período em análise, cf. VAQUINHAS, Irene Maria. Violência, Justiça e Sociedade Rural. Os Campos de Coimbra, Montemor-o-Velho e Penacova de 1858 a 1918. Porto: Edições Afrontamento, 1996, p. 159-177. Sobre a doença, nesse período, veja-se ainda, SAAVEDRA, Mónica Alexandra de Almeida Monteiro. “Uma Questão Nacional”. Enredos da malária em Portugal, séculos XIX e XX. Tese (Doutorado em Ciências Sociais, especialidade de Antropologia Social e Cultural) - Instituto de Ciências Sociais da Universidade de Lisboa, Lisboa, 2010.

${ }^{48}$ A mesma realidade foi registada, em idêntico período, no hospital da Ordem Terceira de Coimbra, cf. SILVA, Ana Margarida Dias da. O Hospital e Asilo da Venerável Ordem Terceira da Penitência de São Francisco de Coimbra 1851-1926. 
meses. O período de internamento foi condicionado por diversos fatores. Além da maior ou menor gravidade da doença, é necessário ter em consideração a situação financeira da Santa Casa. Em períodos de maior dificuldade a instituição tentou abreviar, ao máximo, a permanência de enfermos no hospital. Por exemplo, em outubro de 1881, dado o "estado financeiro, pouco lisougeiro da Sancta Caza da Misericordia desta villa, o lamentavel decrescimento na sua receita e outras circuntancias ainda", tentou-se refrear a entrada de novos doentes e diminuir os períodos de internamento, solicitando que os facultativos concedessem alta hospitalar "logo que da sua sahida não resulte perigo iminente e a serem o mais parcos possiveis nas dietas". ${ }^{49}$ Por outro lado, a capacidade física do espaço e a maior ou menor afluência de doentes terá, com certeza, condicionado os tempos de internamento.

Os que faleceram estiveram, em média, mais tempo internados. As mulheres estiveram hospitalizadas 31 dias, enquanto os homens beneficiaram da assistência hospitalar durante 39 dias. Ainda assim, mais de um terço resistiu somente entre um e sete dias, a saber 37,2 por cento das mulheres e 43,7 por cento dos homens. ${ }^{50}$ Os longos períodos de internamento foram raros, já que apenas quatro doentes estiveram hospitalizados mais do que um ano: duas mulheres e um homem permaneceram naquele espaço entre um e dois anos; enquanto um doente do sexo masculino esteve internado quase cinco anos (1692 dias). Por último, referir que a saída de enfermos do hospital da Misericórdia não sucedeu apenas por alta ou por morte, já que ocorreram situações de abandono por vontade do doente (cinco), de fuga (três) e de transferência para outros hospitais (34).

O sucesso do pequeno hospital administrado pela Santa Casa da Misericórdia de Pombal deveu-se em grande medida à alimentação ministrada aos hospitalizados, o que foi igualmente comum em outros espaços congéneres do passado. Sendo vários os enfermos que no momento da entrada no estabelecimento evidenciaram carências e irregularidades alimentares, advinha-se o peso que as três refeições diárias ministradas aos hospitalizados (almoço, jantar e ceia) tinham na cura ou melhoria desses indivíduos. O sustento dos doentes era realizado à base de pão, leite e carne, sobremaneira vaca e carneiro e menos aves de criação. Era portanto, uma alimentação similar à praticada noutros estabelecimentos hospitalares, existentes à época. De resto, a instituição em apreço procurou guiar a sua atuação neste campo, como noutros, pelos regulamentos e tabelas de outros espaços de maior dimensão, caso do hospital de São José, em Lisboa, e dos hospitais da Universidade de Coimbra, na cidade do Mondego (OLIVEIRA, 2016b, 433-453).

\footnotetext{
Coimbra: Venerável Ordem Terceira da Penitência de São Francisco de Coimbra, 2015. No hospital da Misericórdia de Coruche, no início do século XX, o cenário não foi distinto, cf. CORREIA, Ana Maria Diamantino. A Saúde Pública no Concelho de Coruche 1820-1910. Coruche: Câmara Municipal de Coruche, 2015, p. 112.

${ }^{49}$ Pombal, A.S.C.M.P., Registo da correspondência expedida (1875-1935), fols. 38v-39; Livro de atas (1878-1884), fol. 103.

${ }^{50} \mathrm{~A}$ mesma realidade foi registada em Coimbra, ainda que para um período anterior, cf. LOPES, Maria Antónia. Pobreza, Assistência [...], vol. 1, pp. 777-778.
} 
6. O património móvel do hospital era composto por distintos itens. A par de instrumentos cirúrgicos, têxteis e vasos destinados ao tratamento dos enfermos, existiam objetos talhados à arrecadação, à conservação, à confeção e ao consumo de alimentos, mobiliário e roupa. O arquivo da Santa Casa da Misericórdia de Pombal conserva dois inventários, ambos da segunda metade do século XIX, que permitem estudar os bens existentes no hospital. No primeiro, redigido a 6 de agosto de 1869, foi arrolado um número bastante reduzido de objetos. $\mathrm{O}$ mobiliário registado compreendeu apenas cinco cadeiras de madeira, duas mesas de idêntico material, dois leitos de ferro e um lavatório do mesmo metal. Apesar do inventário não indicar o valor dos itens arrolados, através do livro de receita e despesa, ficamos a saber que os referidos leitos haviam sido adquiridos no ano económico de 1863/64, pela quantia de 10.000 réis..$^{51}$ Os restantes artigos inventariados compreenderam 23 lençóis (sete em estado sofrível), oito colchões (seis novos e os restantes em muito mau estado), sete cobertores de papa, seis fronhas de pano patente (novas) e quatro cabeceiras (novas). ${ }^{52}$

Parece evidente que esta listagem não compreenderia a totalidade do recheio do estabelecimento assistencial. Basta considerar que não foram arroladas candeias, enxergões, esteiras e louça, objetos que sabemos terem sido adquiridos nos anos anteriores e que certamente existiam à data em que foi realizado o inventário. ${ }^{53}$ Esta ideia é reforçada por um aditamento aos utensílios do hospital, realizado a 10 de maio de 1870 , onde surgem de facto arrolados objetos destinados à alimentação e ao curativo dos internados. Para tratamento e higiene dos enfermos existia uma arrastadeira de estanho, uma seringa do mesmo metal e uma banheira de lata. Para armazenamento dos remédios encontravam-se três vidros de xarope, igual número de garrafas pretas e duas brancas. Por sua vez, para alimentação da clientela hospitalar foram inventariados seis pratos de louça de bandel, igual número de tigelas, sendo quatro do mesmo tipo de louça, três colheres de ferro, dois garfos do mesmo material, dois copos de vidro, uma caneca de louça para beber água e um pequeno púcaro de lata. Foram ainda arroladas três bacias de cama e uma de lavar..$^{54}$

Pouco depois, a 19 de dezembro de 1873, foi elaborada uma relação das roupas e mais objetos pertencentes ao hospital, que se achavam em poder da enfermeira Mariana Alves. ${ }^{55} \mathrm{O}$ documento, redigido e assinado pelo cartorário José Libânio da Fonseca Borges, arrolou um total de 292 objetos, compreendendo mobílias, petrechos de enfermaria, utensílios de refeitório e têxteis. A esmagadora maioria dos itens estava em boas condições, já que apenas

\footnotetext{
${ }^{51}$ Pombal, A.S.C.M.P., Livro de receita e despesa (1828-1871), fol.121. No mesmo ano, foram adquiridos colchões, enxergões e um lavatório (provavelmente o referido no inventário) o que teve um custo total de 10.980 réis, quantia que incluiu o preço do transporte desses objetos.

${ }^{52}$ Pombal, A.S.C.M.P., Inventário dos fundos e alfaias (1869), fols. 30-30v. Este inventário foi já transcrito por MORA, Amadeu Cunha. Esboço Histórico [...], p. 86.

${ }^{53}$ Pombal, ASCMP, Livro de receita e despesa (1828-1871), fols. 76, 79, 95, 96, 97, 99, 105 e 121.

${ }^{54}$ Pombal, A.S.C.M.P., Inventário dos fundos e alfaias (1869), fols. 31v-32.

${ }^{55}$ Pombal, A.S.C.M.P., Inventário dos fundos e alfaias (1869), fols. $33 \mathrm{v}-34 \mathrm{v}$ e documento avulso existente no mesmo livro intitulado Relação de roupas e mais objectos pertencentes ao hospital, em poder da enfermeira Marianna Alves.
} 
foi referido o mau estado de conservação de cinco itens. Lamentavelmente, o documento não indica o valor dos bens nem, tão-pouco, a data de aquisição dos mesmos.

Entre os têxteis contavam-se peças destinadas a leitos, a vestuário e a curativo de enfermos. Relativamente à roupa de cama, existiam 48 lençóis, a maior parte dos quais em pano-cru, 16 cobertores, oito cabeceiras, igual número de fronhas, seis cobertas de chita e quatro encerados. Entre as peças de indumentária figuravam cinco camisas, sendo três para homem e duas para mulher. Para tratamento dos doentes existiam seis ligaduras de pano-cru, novas, e quatro apertadeiras do mesmo tecido. Refira-se ainda a existência de seis guardanapos e de outras tantas toalhas: três de linho com renda e igual número de pano-cru, sem renda.

No que toca ao mobiliário, foram inventariadas seis camas de ferro, igual número de mesas-de-cabeceira ${ }^{56}$, três mesas com gavetas, idêntica quantidade de cadeiras de madeira e um lavatório em ferro. $\mathrm{O}$ catálogo deu ainda conta de oito colchões, cujo enchimento seria seguramente de palha de centeio ${ }^{57}$, sendo de estranhar a ausência de um biombo comprado em dezembro de 1872. Para higiene dos enfermos existiam sete bacias de cama, três para as mãos, um bidé, um lavatório de ferro e uma lata para depósito das imundícies.

Para confeção das refeições e degustação dos alimentos existiam 24 pratos de louça de bandel, 18 tigelas, nove garrafas de diferentes cores e tamanhos, seis colheres, igual número de garfos, cinco canecas, três colheres de chá e duas panelas de lata. Por seu turno, entre os objetos destinados ao tratamento dos internos, além das ligaduras já referidas, contavam-se 19 vidros pequenos para xaropes e esfregações, seis púcaros para unturas, uma seringa epidérmica, outra de estanho e uma arrastadeira da mesma liga metálica. Entre os bens menos usuais mencione-se um tinteiro, uma lamparina para iluminação do espaço e um saca-rolhas.

Nos anos imediatos e até final do período em estudo, a Misericórdia foi adquirindo regularmente vários e distintos objetos. Por exemplo, no ano económico de 1874/75, a confraria despendeu 23.525 réis com a aquisição e o conserto de diferentes utensílios do hospital, com destaque para a compra de dois cobertores no estabelecimento da viúva Bastos (8.000 réis), de uma cama de pau, executada pelo carpinteiro Manuel Mendes (4.900 réis), e de três enxergões, confecionados pelo colchoeiro José Gaspar (2.040 réis).$^{58}$ Entre os artigos de menor monta refira-se a aquisição de seis guardanapos (120 réis), seis pratos e três canecas (330 réis), quatro taças para escarradeiras (140 réis), três oleados para as camas dos doentes (1.200 réis), três bacias de cama (540 réis), duas ditas para as mãos (400 réis), duas toalhas (600

\footnotetext{
${ }^{56}$ Parece tratar-se das seis mesas-de-cabeceira executadas pelo marceneiro Bernardo de Sousa, a quem o tesoureiro da Misericórdia pagou 4.800 réis, no dia 12 de setembro de 1873, cf. Pombal, A.S.C.M.P., Diário da receita e despesa (1871-1874), fl. 139.

${ }^{57}$ Pombal, A.S.C.M.P., Diário da receita e despesa (1871-1874), fols. 132 e 143.

${ }^{58}$ Pombal, A.S.C.M.P., Diário da receita e despesa (1874-1878), fols. 11, 21 e 32.
} 
réis) e palha para a cama de pau (480 réis). ${ }^{59}$ No ano seguinte, entre outros itens, saliente-se a aquisição de um relógio para o hospital (12.000 réis).$^{60}$

O desgaste a que as peças de louça estavam sujeitas obrigava a uma renovação constante, pelo que abundam referências a gastos do género. Por exemplo, em outubro de 1876, foram comprados 24 pratos, 12 tigelas e seis garfos ${ }^{61}$; enquanto em novembro de 1897, foram adquiridas 21 tigelas e 18 pratos na loja de Luís Gaspar, morador no lugar da Calvaria, mas com estabelecimento de louça em Pombal. ${ }^{62}$ Relativamente a talheres refira-se a aquisição no ano de 1880, de seis facas, igual número de garfos, outras tantas colheres de sopa e colheres de chá63; ou ainda os sete garfos, com cabo de osso, e as seis colheres de sopa, compradas em outubro de 1900, na loja de Joaquim Luís Lente, em Pombal. ${ }^{64}$ No que toca à bateria de cozinha, foi registada a compra de panelas, cafeteiras e o conserto de uma chocolateira. Noutros casos, os trastes adquiridos não foram discriminados. Assim, em setembro de 1908, a irmandade pagou 1.080 réis a José Raul da Silva, de Pombal, de utensílios de cozinha que forneceu para o hospital nesse mês ${ }^{65}$; e em junho do ano seguinte, despendeu mais 1.700 réis em utensílios de cozinha feitos pelo mesmo indivíduo. ${ }^{66}$ Além dos itens adquiridos há a assinalar a doação, em 1882, de uma caixa contendo várias coleções de louça para o hospital, cortesia de Duarte Ferreira Pinto Basto, diretor da fábrica da Vista Alegre, no contexto de uma subscrição aberta num periódico local com vista à obtenção de donativos destinados às obras de reconstrução do hospital. ${ }^{67}$

De referir ainda que, para confeção dos alimentos, a Santa Casa adquiriu, no ano económico de 1897/98, um fogão no estabelecimento de José Luís da Cunha \& Irmão, o que teve um custo de 21.900 réis. ${ }^{68}$ As dimensões do novo equipamento, considerado de grande utilidade "não só pelo lado economico mas tambem pelo asseio e facilidade com que ali se preparam e conservam os caldos e outros alimentos a fornecer aos doentes tratados no seu hospital", ${ }^{69}$ obrigaram a rebaixar a lareira da cozinha, trabalho executado pelo pedreiro José Dias Crispiniano, por 820 réis. $^{70}$ Pouco depois, a 31 de outubro, o fogão deu os primeiros sinais

\footnotetext{
${ }^{59}$ Pombal, A.S.C.M.P., Diário da receita e despesa (1874-1878), fols. 14, 15 e 20.

${ }^{60}$ Pombal, A.S.C.M.P., Diário da receita e despesa (1874-1878), fol. 53. A 31 de dezembro de 1884, foi necessário pagar 1.200 réis ao serralheiro Joaquim Mendes de Figueiredo, morador em Pombal, pelo conserto e limpeza do referido relógio, cf. Pombal, A.S.C.M.P., Diário da receita e despesa (1878-1887), fol. 156. Sobre a necessidade de adquirir estes objetos para os hospitais, cf. ARAÚJO, Maria Marta Lobo de. A Misericórdia de Vila Viçosa [...], p. 118.

${ }^{61}$ Pombal, A.S.C.M.P., Diário da receita e despesa (1874-1878), fol. 100.

${ }^{62}$ Pombal, A.S.C.M.P., Diário da receita e despesa (1895-1905), fol. 55.

${ }^{63}$ Pombal, A.S.C.M.P., Livro de atas (1878-1884), fol. 70.

${ }^{64}$ Pombal, A.S.C.M.P., Diário da receita e despesa (1895-1905), fol. 119.

${ }^{65}$ Pombal, A.S.C.M.P., Diário da receita e despesa (1905-1932), fol. 63.

${ }^{66}$ Pombal, A.S.C.M.P., Diário da receita e despesa (1905-1932), fol. 68.

${ }^{67} O$ Pombalense, ano 6, n. ${ }^{\circ} 246$, de 18 de abril de 1882. A caixa que transportou a louça foi depois vendida por 100 réis, cf. Pombal, A.S.C.M.P., Diário da receita e despesa (1878-1887), fol. 139v.

${ }^{68}$ Pombal, A.S.C.M.P., Diário da receita e despesa (1895-1905), fol. 76.

${ }^{69}$ Pombal, A.S.C.M.P., Livro de registo de orçamentos (1891-1905), fol. 53.

${ }^{70}$ Pombal, A.S.C.M.P., Diário da receita e despesa (1895-1905), fol. 80.
} 
de desgaste, obrigando a corporação a gastar 360 réis com o serralheiro Alfredo da Silva, pelo conserto de uma torneira e da caldeira. ${ }^{71}$

No que respeita a têxteis são dignas de registo as aquisições feitas em junho de 1881: 24 travesseiros (4.956 réis), igual número de fronhas (1.960 réis), 12 cabeceiras (3.000 réis), seis toalhas de linho para as mãos (1.770 réis), outras tantas de algodão (1.004 réis), quatro camisas (2.100 réis) e uma toalha de altar para administrar o viático aos enfermos (530 réis). ${ }^{72}$ Para guardar a roupa do hospital, em junho de 1896, a Misericórdia encomendou uma arca ao carpinteiro José Maria de Novais, morador em Pombal, trabalho que importou 2.130 réis. ${ }^{73}$ Destaque ainda para os 60.680 réis despendidos, em junho de 1905, com a compra de colchas, cobertores, panos-crus e toalhas no estabelecimento de J. J. Gonçalves \& Companhia, localizado em Lisboa, na rua dos Bacalhoeiros. ${ }^{74}$ De resto, o investimento feito pela irmandade nesse ano económico de 1904/05, no que respeita à aquisição de objetos para o hospital, foi assinalável. É que à despesa já mencionada é necessário somar 66.200 réis, quantia que compreendeu a compra de seis camas de ferro, quatro camareiras e 11 guarnecimentos completos, adquiridos em Pombal, na loja de José Luís da Cunha E Irmão. ${ }^{75}$

No que toca a utensílios destinados ao tratamento dos doentes, além de compressas e ligaduras, refira-se a compra de uns elásticos para óculos, em fevereiro de $1877 ;{ }^{76}$ uma bacia de lata para lavagem de feridas, adquirida em novembro de 1881 (300 réis); ${ }^{77}$ um instrumento para clisteres, comprado em 1881/82 (900 réis) ${ }^{78}$ uma maca para transporte de doentes, feita em junho de 1881, pelo carpinteiro António Roque, de Pombal (3.550 réis); ${ }^{79}$ uma seringa de zinco, adquirida em Lisboa, no ano económico de 1881/82 (900 réis); ${ }^{80}$ e vários instrumentos cirúrgicos, comprados na mesma cidade, em maio de 1898 (4.500 réis). ${ }^{81}$

7. Na segunda metade do século XIX, a Santa Casa da Misericórdia de Pombal continuou a ser uma das principais instituições da vila, fruto do seu estatuto jurídico especial, dos indivíduos que a integraram e dominaram, do património que possuiu, da administração do único hospital da vila, da atividade creditícia que continuou a desenvolver e das práticas assistenciais que levou a efeito. Pese as fragilidades e as limitações sentidas, continuou a deter

\footnotetext{
${ }^{71}$ Pombal, A.S.C.M.P., Diário da receita e despesa (1895-1905), fol. 85.

${ }^{72}$ Pombal, A.S.C.M.P., Diário da receita e despesa (1878-1887), fols. 53-54.

${ }^{73}$ Pombal, A.S.C.M.P., Diário da receita e despesa (1895-1905), fol. 15.

${ }^{74}$ Pombal, A.S.C.M.P., Diário da receita e despesa (1895-1905), fol. 192.

${ }^{75}$ Pombal, A.S.C.M.P., Diário da receita e despesa (1895-1905), fol. 190

${ }^{76}$ Pombal, A.S.C.M.P., Diário da receita e despesa (1874-1878), fol. 108.

${ }^{77}$ Pombal, A.S.C.M.P., Diário da receita e despesa (1878-1887), fol. 73.

${ }^{78}$ Pombal, A.S.C.M.P., Livro da receita e despesa (1869-1905), fol. 39.

${ }^{79}$ Pombal, A.S.C.M.P., Diário da receita e despesa (1878-1887), fol. 56.

${ }^{80}$ Pombal, A.S.C.M.P., Diário da receita e despesa (1878-1887), fol. 88.

${ }^{81}$ Pombal, A.S.C.M.P., Diário da receita e despesa (1895-1905), fol. 72.
} 
um papel essencial, permanecendo, em muitos casos, a única instituição capaz de prestar algum auxílio aos necessitados residentes no concelho e aos pobres em trânsito.

Embora tenha continuado a levar a cabo um leque alargado de práticas assistenciais, tais como esmolas a doentes pobres tratados no domicílio, emissão de cartas de guia e auxílio aos pobres transeuntes, assistência aos presos pobres (embora, no período em análise, não fosse matéria da sua competência), apoio a recém-nascidos e a jovens, enterro de irmãos e respetivas esposas, dos pobres falecidos no hospital e dos que mediante pagamento queriam ser conduzidos à sepultura na tumba da irmandade, a assistência hospitalar passou a constituir a modalidade assistencial mais relevante da instituição. Os livros de receita e despesa evidenciam essa realidade. Se no final da década de 30, a Misericórdia canalizava a maior parte dos seus recursos para o sector religioso, nas décadas seguintes o cenário modificou-se, passando a destinar a maior fatia da despesa ao sector da saúde. Os problemas financeiros não impediram a irmandade de empreender esforços no sentido de melhorar o local onde os doentes pobres eram recebidos. À escassez de rendimentos e às dificuldades em cobrar juros e foros, os irmãos responderam com novas formas de angariar fundos. Bazares, espetáculos, saraus e, sobretudo, subscrições possibilitaram reconstruir o hospital na década de 80 , do século XIX, empreendimento maior dessa centúria, em que reconhecidamente se empenharam todos os confrades.

A análise dos inventários oitocentistas permitiu conhecer o recheio do hospital e o estado de conservação dos bens arrolados: mobiliário, têxteis, utensílios de cozinha e de refeitório, objetos ligados à cura e à higiene dos enfermos e vasos destinados à conservação de remédios. Possibilitou apurar elementos sobre os materiais, a cor e o tamanho dos objetos, os tipos de louça e de tecido, mas nunca o valor dos bens ou a data de aquisição dos mesmos, ainda que o cruzamento com livros e diários de receita e despesa tenha possibilitado conhecer alguns dados a respeito. Pese as listagens não compreenderem a totalidade do recheio do estabelecimento, os catálogos evidenciam a reduzida dimensão e capacidade do espaço. Sem prejuízo, comparando os dois inventários, verifica-se que num curto período de tempo a Misericórdia aumentou consideravelmente o número de leitos de ferro, passando estes de dois para seis. Mas além das camas, que possibilitaram o aumento do número de doentes admitidos em simultâneo, ampliou bastante o número de lençóis, de pratos, de talheres e de vidros de xaropes. Ou seja, existiu um esforço por parte da instituição de dotar aquele espaço dos utensílios necessários ao tratamento de um número superior de enfermos. A Relação de roupas e mais objectos pertencentes ao hospital, em poder da enfermeira Marianna Alves, elaborada em 1873, parece apontar ainda para a necessidade que a Santa Casa sentiu de zelar pelo seu património móvel, exercendo um controlo mais efetivo sobre os objetos à guarda daquela assalariada, tanto mais que a sua conduta, à semelhança das suas antecessoras, havia de pautar-se por faltas graves que haveriam de conduzir ao seu despedimento e ao de seu marido, o enfermeiro-ajudante. 
O estudo dos diários de receita e despesa evidenciou a compra regular de objetos para o hospital, sobretudo apetrechos de cozinha e de degustação dos alimentos, mas também de têxteis, como cobertores, colchas, toalhas e travesseiros, itens adquiridos sobretudo em Pombal mas também em Lisboa. Quanto aos estabelecimentos onde esses objetos eram adquiridos, verificou-se que, não raras vezes, pertenciam a indivíduos ligados à irmandade, caso do negociante José Luís da Cunha que foi provedor da instituição. A ligação à irmandade também terá pesado no momento de encomendar a execução de determinados utensílios. Foi o caso da maca produzida em 1881 pelo carpinteiro António Roque ou da arca que o carpinteiro José Maria de Novais realizou em 1896, já que ambos eram irmãos da Misericórdia.

O estudo do património móvel do hospital revelou ainda aspetos relativos à alimentação dos enfermos, pois embora a aquisição de café e de chocolate jamais ter sido mencionada, a compra de várias cafeteiras e o conserto de uma chocolateira evidenciam o consumo desses produtos. Por último, referir que a compra de um relógio parece apontar para uma maior regulamentação e rigor do quotidiano hospitalar, designadamente no que respeita ao cumprimento dos horários das dietas, das boticas prescritas pelos facultativos e das visitas, auspícios de um regulamento privativo desejado, trabalhado por uma comissão designada para o efeito, mas que não parece ter sido concluído.

\section{Referências}

\section{Fontes Manuscritas}

Leiria, Arquivo Distrital de Leiria (A.D.L.)

Governo Civil:

Correspondência de Administradores do Concelho, cx. 5 (1848-1863), III-47-E-1.

Correspondência de Administradores do Concelho, cx. 6 (1864-1885), III-47-E-2.

Licenciamento e Fiscalização, Santa Casa da Misericórdia de Pombal, 01-III-74-D-4.

Registos Notariais, Pombal, V-104-A-56.

Lisboa, Arquivo Nacional Torre do Tombo (A.N.T.T.)

Desembargo do Paço, Corte, Estremadura e Ilhas, mç. 125, doc. 28; mç. 125, doc. 39; mç. 641, doc. 6; mç. 647, doc. 31; mç. 802, doc. 1; mç 1560, doc. 9. 
Pombal, Arquivo da Santa Casa da Misericórdia de Pombal (A.S.C.M.P.)

Breves para redução de missas e encargos pios.

Diário da receita e despesa (1871-1874).

Diário da receita e despesa (1874-1878).

Diário da receita e despesa (1878-1887).

Diário da receita e despesa (1895-1905).

Diário da receita e despesa (1905-1932).

Inventário dos fundos e alfaias (1869).

Livro de atas (1844-1862).

Livro de atas (1862-1871).

Livro de atas (1871-1878).

Livro de atas (1878-1884).

Livro de atas (1884-1903).

Livro de atas (1903-1910).

Livro primeiro das entradas dos irmãos.

Livro de receita e despesa (1828-1871).

Livro de receita e despesa (1869-1905).

Livro de registo de orçamentos (1891-1905).

Livro de títulos da Santa Casa de Pombal (1821).

Registo da correspondência expedida (1875-1935).

Relação de roupas e mais objectos pertencentes ao hospital, em poder da enfermeira Marianna Alves. 


\section{Fontes Impressas}

Collecção Chronologica da Legislação Portugueza, compilada e anotada por José Justino de Andrade e Silva, 1620-1627. Lisboa: Imprensa de J. J. A. Silva, 1855.

COSTA, António Carvalho da. Corografia Portugueza, e Descripçam Topografica do Famoso Reyno de Portugal. Tomo III. Lisboa: Oficial Real Deslandesiana, 1712.

Pombalense (O), ano 6, 1882.

\section{Estudos}

ABREU, Laurinda. Memórias da Alma e do Corpo. A Misericórdia de Setúbal na Modernidade. Viseu: Palimage Editores, 1999.

ABREU, Laurinda. A Santa Casa da Misericórdia de Setúbal de 1500 a 1755: Aspectos de sociabilidade e poder. Setúbal: Santa Casa da Misericórdia de Setúbal, 1990.

ARAÚJO, Maria Marta Lobo de. Dar aos pobres e emprestar a Deus: as Misericórdias de Vila Viçosa e Ponte de Lima (Séculos XVI-XVIII). Barcelos: Santa Casa da Misericórdia de Vila Viçosa, Santa Casa da Misericórdia de Ponte de Lima, 2000.

ARAÚJO, Maria Marta Lobo de. A Misericórdia de Vila Viçosa: de finais do Antigo Regime à República. Vila Viçosa: Santa Casa da Misericórdia de Vila Viçosa, 2010.

ARAÚJO, Maria Marta Lobo de (coord.). A Intemporalidade da Misericórdia. As Santas Casas Portuguesas: Espaços e Tempos. Braga: Santa Casa da Misericórdia de Braga, 2016.

CASTRO, Armando de. "Orizicultura”. In: SERRÃO, Joel (Dir.) Dicionário de História de Portugal. Vol. IV. Lisboa: Pário. Porto: Livraria Figueirinhas, 1984, p. 479-481.

CORREIA, Ana Maria Diamantino. A Saúde Pública no Concelho de Coruche 1820-1910. Coruche: Câmara Municipal de Coruche, 2015.

LOPES, Maria Antónia. Pobreza, Assistência e Controlo Social em Coimbra (1750-1850). 2 vols. Viseu: Palimage Editores, 2000.

MORA, Amadeu Cunha. Esboço Histórico da Santa Casa da Misericórdia de Pombal. Pombal: Santa Casa da Misericórdia de Pombal, 2010 (reimpressão da edição de 1953). 
OLIVEIRA, Ricardo Pessa de. História da Santa Casa da Misericórdia de Pombal (1628-1910). Pombal: Santa Casa da Misericórdia de Pombal, 2016a.

OLIVEIRA, Ricardo Pessa de. "Saúde e Dieta Alimentar. Os Doentes Assistidos pela Misericórdia de Pombal (1850-1910)". In: PINHEIRO, Joaquim e SOARES, Carmen (coord.) Patrimónios Alimentares de Aquém e de Além-Mar. Coimbra: Imprensa da Universidade de Coimbra. São Paulo: Annablume, 2016b, p. 433-453.

PAIVA, José Pedro (coord.). Portugaliae Monumenta Misericordiarum. 9 vols. Lisboa: União das Misericórdias Portuguesas, 2002-2011.

REIS, Célia. A Misericórdia de Torres Vedras (1520-1975). Torres Vedras: Santa Casa da Misericórdia de Torres Vedras, 2016.

SÁ, Isabel dos Guimarães. As Misericórdias Portuguesas de D. Manuel I a Pombal. Lisboa: Livros Horizonte, 2001.

SÁ, Isabel dos Guimarães. Quando o rico se faz pobre: Misericórdias, caridade e poder no império português 1500-1800. Lisboa: Comissão Nacional para as Comemorações dos Descobrimentos Portugueses, 1997.

SAAVEDRA, Mónica Alexandra de Almeida Monteiro. "Uma Questão Nacional". Enredos da malária em Portugal, séculos XIX e XX. Tese (Doutorado em Ciências Sociais, especialidade de Antropologia Social e Cultural) - Instituto de Ciências Sociais da Universidade de Lisboa, Lisboa, 2010.

SILVA, Ana Isabel. A Arte de Enfermeiro: Escola de Enfermagem Dr. Ângelo da Fonseca. Coimbra: Imprensa da Universidade de Coimbra, 2008.

SILVA, Ana Margarida Dias da. O Hospital e Asilo da Venerável Ordem Terceira da Penitência de São Francisco de Coimbra 1851-1926. Coimbra: Venerável Ordem Terceira da Penitência de São Francisco de Coimbra, 2015.

SILVA, Helena Sofia Rodrigues Ferreira da. Do curandeiro ao diplomado: história da profissão de enfermagem em Portugal (1886-1955). Tese (Doutorado em História, área de conhecimento Idade Contemporânea) - Universidade do Minho, Braga, 2010.

VAQUINHAS, Irene Maria. Violência, Justiça e Sociedade Rural. Os Campos de Coimbra, Montemor-o-Velho e Penacova de 1858 a 1918. Porto: Edições Afrontamento, 1996.

Recebido em: 14-06-2017

Aceito em: 20-07-2017 